\title{
Síntesis del Encuentro Internacional sobre Ecología y Manejo de bosques de Quercus bajo una perspectiva de Cambio Global
}

\author{
I.M. Pérez-Ramos ${ }^{1, *}$, R. Villar², T. Marañón ${ }^{1}$ \\ (1) IRNAS, CSIC, Av. Reina Mercedes, 10, P.O. Box 1052. 41080 Sevilla, España \\ (2) Área de Ecología, Facultad de Ciencias, Universidad de Córdoba. 14071 Córdoba, España
}

* Autor de correpondencia: I.M. Pérez-Ramos [imperez@irnase.csic.es]

> Recibido el 31 de octubre de 2013, aceptado el 08 de noviembre de 2013.

Pérez-Ramos, I.M., Villar, R., Marañón, T. 2013. Síntesis del Encuentro Internacional sobre Ecología y Manejo de bosques de Quercus bajo una perspectiva de Cambio Global. Ecosistemas 22(3):141-142. Doi.: 10.7818/ECOS.2013.22-3.23

Entre los días 30 de Septiembre y 2 de Octubre de 2013 tuvo lugar en Baeza (Jaén) un encuentro Internacional titulado "Oak forests coping with Global Change: ecology and management", donde se trataron diversos aspectos relacionados con la filogeografía, genética, demografía, ecofisiología, vulnerabilidad, gestión y conservación de las especies de Quercus frente al Cambio Global. El encuentro estuvo financiado por la Universidad Internacional de Andalucía (UNIA), que se hizo cargo de la logística y nos proporcionó un enclave único e inmejorable para llevar a cabo este encuentro: su sede en Baeza, ciudad de estilo renacentista declarada por la UNESCO como Patrimonio de la Humanidad.

A pesar del limitado aforo que lleva implícito este tipo de talleres, el encuentro atrajo la atención de 40 participantes procedentes de varias universidades y centros de investigación repartidos por diferentes partes del mundo (Francia, Portugal, Inglaterra, Italia, Holanda, México y España). La discusión y el intercambio de ideas entre los participantes fueron promovidos mediante 15 ponencias invitadas, 11 comunicaciones cortas y 22 pósteres, que fueron distribuidos en 7 sesiones temáticas diferentes. La primera sesión estuvo representada por Arndt Hampe (Instituto Nacional de Investigación Agraria en Burdeos, Francia), que puso de manifiesto la utilidad de los estudios filogeográficos para reconstruir el pasado y tratar de predecir la respuesta futura de los bosques de Quercus frente a los riesgos derivados del Cambio Global. Antonio González Rodríguez (Universidad Nacional Autónoma de México, Morelia) y María Valbuena (Universidad Politécnica de Madrid) centraron sus ponencias sobre aspectos relacionados con la variabilidad genética y el proceso de hibridación entre especies de Quercus en México y en la península ibérica, respectivamente. En la sesión sobre "Resiliencia de especies de Quercus frente al cambio global” Miguel Ángel Zavala (Universidad de Alcalá, Madrid) presentó modelos y aproximaciones teóricas, mientras que Jofre Carnicer (Universidad de Groningen, Holanda) resumió los resultados de experimentos que simulan el cambio climático. Ignacio M. Pérez-Ramos (Instituto de Recursos Naturales y Agrobiología, Sevilla) y Fernando Pulido (Universidad de Extremadura, Plasencia) nos ofrecieron una visión general del proceso de reclutamiento de especies de Quercus en bosques y dehesas, desgranando los principales factores que lo limitan y su respuesta potencial a los riesgos derivados del Cambio Global. En la sesión sobre estrés hídrico, Jesús J. Camarero (Instituto Pirenaico de Ecología, Zaragoza) revisó los procesos de decaimiento y sus causas, Ismael Aranda (Centro de Investigación Forestal, Madrid) centró su ponencia en los mecanismos eco-fisiológicos que desarrollan las plantas de Quercus en respuesta al estrés hídrico y Rafael Villar (Universidad de Córdoba) presentó resultados de crecimiento y los factores que lo controlan en las distintas fases demográficas. La sesión sobre "Conservación y manejo" estuvo representada por Pilar Fernández Rebollo (Universidad de Córdoba), Vanda Acácio (Universidad de Lisboa, Portugal) y Mario González Espinosa (ECOSUR, México), que nos presentaron la problemática derivada de la gestión y manejo de las dehesas españolas, los "montados" portugueses y los bosques montanos mejicanos, respectivamente. Finalmente, Teodoro Marañón (Instituto de Recursos Naturales y Agrobiología, Sevilla) en la sesión sobre "Conclusiones del encuentro", ofreció una visión general de las principales líneas y "huecos" en la investigación sobre ecología y manejo de bosques de Quercus. El encuentro contó además con una mesa redonda sobre "Servicios ecosistémicos y manejo de las dehesas", en la que Javier Navarrete (Consejería de Medio Ambiente, Junta de Andalucía) presentó los objetivos principales del proyecto europeo Life bio-Dehesa y donde se debatieron diferentes aspectos relacionados con la gestión y provisión de servicios en estos sistemas tan complejos dominados por especies de Quercus.

El debate desde diferentes aproximaciones (filogeográfica, genética, demográfica, ecofisiológica y aplicada) sobre estas especies de árboles pone de manifiesto la alta diversidad temática que ronda en torno a la investigación de este género tan emblemático, que alberga numerosas especies de alto interés ecológico y socio-económico. Los organizadores queremos agradecer a la Universidad Internacional de Andalucía y a Lourdes Soria (coordinadora del evento) el haber hecho posible este encuentro, y a todos los asistentes y participantes del encuentro por su gran entusiasmo y alto grado de participación en las diferentes sesiones. Para una información más detallada del Taller se puede consultar la página web: www.anasinque.com. 


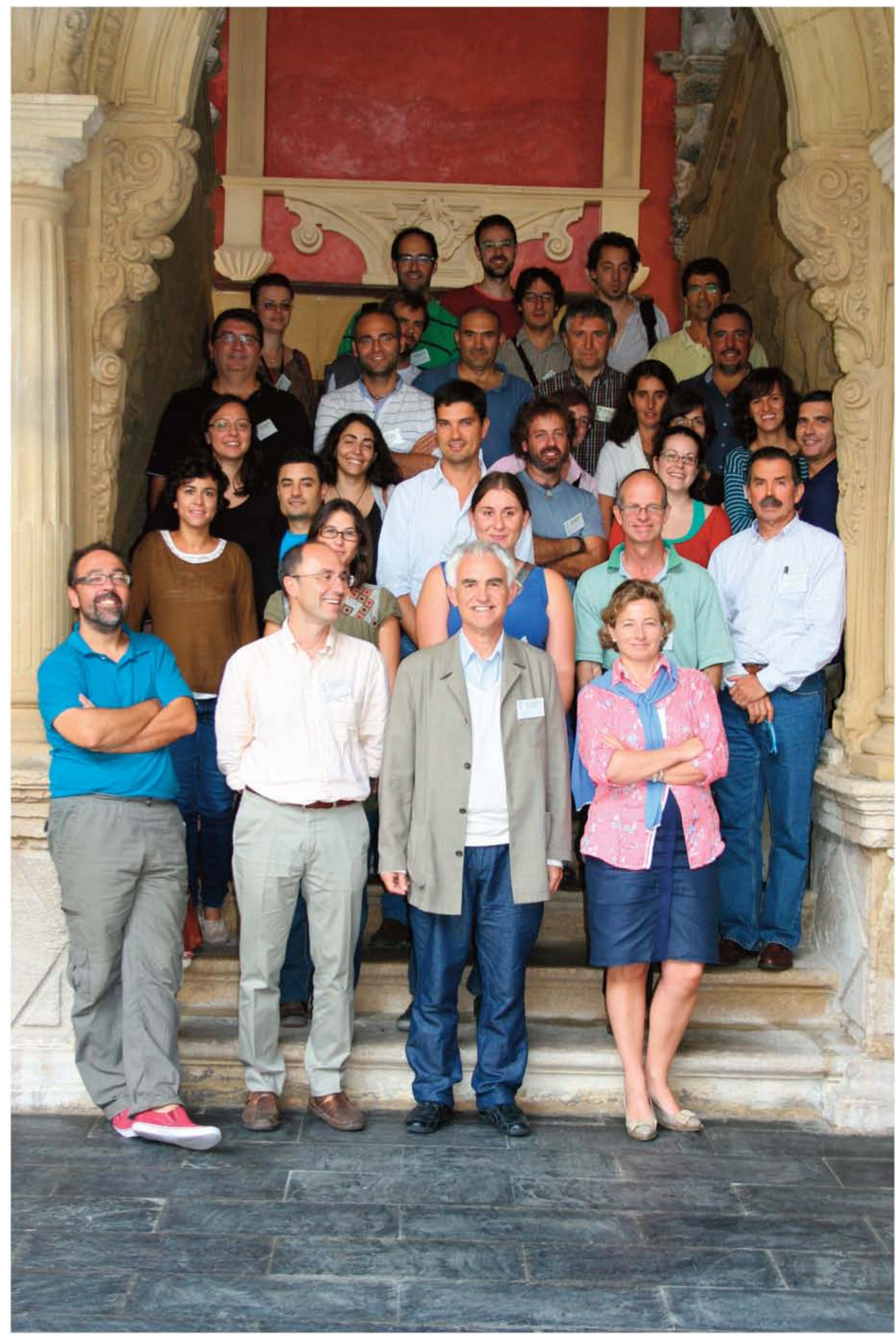

Figura 1. Participantes en el Taller Internacional sobre "Ecología y Manejo de bosques de Quercus bajo una perspectiva de Cambio Global" (Octubre 2013), en la escalera barroca del Palacio de Jabalquinto, Sede Antonio Machado de la UNIA, Baeza, Jaén. (Foto: Carlos Serrano). 